\title{
Los estudiantes tras las cámaras: el recurso de la novela para la historia.
}

\section{Resumen}

Aquí se exploran las representaciones colectivas, el escenario familiar, cotidiano y afectivo de los estudiantes de mediados de 1960 en la Universidad Nacional (UN) en Bogotá, y de los primeros años de 1970 en la Universidad de Antioquia (UdeA), en Medellín. El objetivo: acercarse a la historia transcurrida tras las cámaras de la historiografía político-social tradicionalmente encargada del sujeto en cuestión, la cual creó un acervo, pero también un objeto desde una mirada particular. Las fuentes: dos novelas, Compañeros de viaje (1991) de Luis Fayad y El dedo índice de Mao (1993) de Juan Diego Mejía. El ejercicio permitió aproximarse a la escena privada y domestica estudiantil, reflexionar sobre el vínculo de esta con la vida pública y social y sobre la injerencia de las razones afectivas en los motivos de la vinculación o la militancia, así como interpretar la manera como significaron y enfrentaron el mundo en que vivieron, a partir de indicios y datos tipificados encontrados en las novelas. Finalmente, el artículo es una forma de demostrar y corroborar la eficacia del uso de la novela como fuente, que parece depender más de las capacidades del investigador que de las cualidades del material.

Palabras claves representaciones colectivas, escena familiar, escena cotidiana, escena afectiva, estudiantes colombianos, novela como fuente.

\begin{abstract}
Here we explore the collective representations, family, everyday life and emotional stage of the 1960 students at the Universidad Nacional in Bogota, and the early 1970s at the Universidad de Antioquia in Medellin. The object: approaching the history behind the camera elapsed traditionally in charge of social and political historiography of the subject in question, which created a collection, but also an object from a particular look. The sources: two novels, Compañeros de viaje of Luis Fayad and El dedo índice de Mao of Juan Diego Mejia. This exercise allowed to approach the private and domestic scene of students, reflect on the link on this with public and social life and about interference of emotional reasons on the grounds of linkage or militancy, and to interpret the way they meant and they faced the
\end{abstract}


world in which they lived, from the evidence and classified data found in both novels. Finally, the article is a way to demonstrate and substantiate the efficacy of the novel as a source, which seems to depend more on the capacities of the research that the qualities of the material.

Keywords collective representations, familiar stage, everyday stage, emotional stage, students, novel as source.

\section{Introducción ${ }^{1}$}

Saussure (citado por Bourdieu 51) hace la siguiente proposición: “el punto de vista crea el objeto". En ese segundo capítulo del Oficio del sociólogo, titulado La construcción del objeto (1975), Bourdieu basándose en Max Weber, recuerda lo real como producto y apropiación del pensamiento. De ninguna manera tiene esto que ver con las trivialidades postmodernistas del relativismo ni de las narraciones como simples versiones. En esa disertación el sociólogo francés, de alguna manera, nos invita, entre otras cosas, a pensar en la ciencia y en el pensamiento científico como fenómenos mismos de estudio, como construcciones o apropiaciones. Cita a Marx:

La totalidad concreta, como totalidad del pensamiento, como un concreto del pensamiento es, in fact, un producto del pensamiento y de la concepción (...). El todo, tal como aparece en la mente, como todo del pensamiento, es un producto de la mente que piensa y que se apropia el mundo del único modo posible, modo que difiere de la apropiación de ese mundo en el arte, la religión, el espíritu práctico. (51)

\footnotetext{
${ }^{1}$ Este artículo está basado en la tesis "La novela como fuente para la historia cultural: los estudiantes en Compañeros de viaje y en El dedo índice de Mao", elaborada para obtener el título de Licenciado en Ciencias Sociales en la Universidad de Cundinamarca (Colombia). La tesis fue reconocida como meritoria. A su vez este artículo comparte una versión ampliada y mejorada de una preliminar que fue publicada por la Revista Representaciones Sociales y Culturales, № 19.
} 
Además de los propósitos científicos singulares con que Bourdieu haya escrito esas líneas, allí logra hacernos pensar que existe un elemento que no se puede dejar pasar desapercibido a la hora de realizar los balances historiográficos que nos permiten acomodarnos en la tradición de la disciplina: todo trabajo, como producto del pensamiento, es una apropiación de lo real. En nuestro caso específico, este es un estimulante para optar por una actitud y actividad de cuestionamiento frente a las construcciones del pasado colombiano que han hecho los historiadores, suponiendo que sea posible alejarse de una pasividad impresa en la manera como usamos, asimos y aprehendemos los acervos historiográficos.

El punto de vista predominante en el caso estudiantil ha sido el de la historia política y el de la historia social. Desde allí se ha visitado con predilección a las décadas de 1960 y 1970, por lo menos con mayor atención que al resto de la segunda mitad del siglo y ciertamente muy por encima de la escasa observación sobre la primera mitad. Estas reconstrucciones nos presentaron a los estudiantes con una personalidad decididamente politizada en el contexto de los años 60 y 70: partícipes de un sector que se asomaba con nobles apetitos revolucionarios, críticos, a un presente en el cual el sueño de un futuro mejor lanzaba el desafío de una vida ascética, disciplinada y comprometida. Estudiantes que recibieron formación político-militar en Cuba y que intentaron crear focos guerrilleros en Colombia (caso MOEC 7 de enero ${ }^{2}$, por ejemplo); estudiantes que gritaron “¡viva Camilo!"”, que sentaron su voz contra la acción norteamericana en

\footnotetext{
${ }^{2}$ El Movimiento Obrero Estudiantil Campesino 7 de Enero, fue un destacado actor político de la década del sesenta que dio origen a la Nueva Izquierda en Colombia (Diaz, El movimiento). La Nueva Izquierda, a su vez, se caracterizó por representar "un intento de renovar ideal revolucionario en los años 60 por parte de grupos y organizaciones al margen de los viejos partidos obreros socialistas y comunistas" (Archila, El maoísmo). Estos fueron principalmente abstencionistas y se mostraban a favor de la lucha armada como medio para logar cambios sociales.

${ }^{3}$ Camilo Torres Restrepo (1929-1966), fue un sacerdote colombiano, cofundador de la facultad de sociología de la Universidad Nacional, y profesor de la misma universidad, que influyó decisivamente en el movimiento estudiantil. Sus cercanías con los jóvenes así como sus ideas de denuncia sobre un cristianismo que antes de procurar el amor al prójimo justificaba la dominación, le granjearon los señalamientos de la curia así como la devoción política del estudiantado. Camilo Torres ingresó a las filas de la guerrilla denominada Ejército de Liberación Nacional, donde murió el 15 de febrero de 1966.
} 
Vietnam y que descalificaron categóricamente la invasión a República Dominicana; que no se amilanaron ante la represión estatal, que tenían una productiva desconfianza de la promesas del gobierno de turno. En fin, estudiantes que asumieron con gallardía el reto histórico que les tocó vivir ${ }^{4}$. De manera, pues, que no sólo han desocultado una importante parte del pasado de los estudiantes; al hacerlo participaron en la creación de un objeto, y de paso en la producción de una suerte de imaginario fundado en sus predilecciones analíticas. Cuando la mirada señala una única arista y sobre ella vuelve reiterada y exclusivamente, se corre el riesgo de que una de las partes se presente como el todo. Los sujetos críticos, intelectuales, revolucionarios, disidentes, que han sido materia de investigación, tienen un rostro, las más de las veces heroico, que obnubila, oscurece, y por eso mismo convierte en zonas de gran interés, a esos otros rostros suyos que la mirada política no alcanza a fotografiar.

Durante los años 60 y 70, la política tiñó todos los escenarios del momento histórico. Sin embargo, no todos esos escenarios eran exclusivamente políticos como las asambleas, donde tenían lugar confrontaciones simbólicas entre distintos grupos que se disputaban el prestigio de sus identidades colectivas antes que pactar la agenda de movilización-, y no todos los esfuerzos estudiantiles estuvieron abocados a la disidencia y a la revolución. Sin olvidar el elemento político pero sin dejarlo tampoco en primera instancia, el trabajo de escudriñar los escenarios familiar-afectivo-cotidiano de los estudiantes - así como los aspectos no principalmente políticos dentro de un escenario que sí lo es-, puede arrojar otros resultados, producto de la ampliación del objeto mediante una ampliación de la mirada, que tridimensionalicen al sujeto en cuestión.

Se abren preguntas como las siguientes: ¿qué hacían los estudiantes cuando no estaban en asambleas, en marchas o haciendo la revolución? ¿Cómo

\footnotetext{
${ }^{4}$ Nos referimos principalmente a los trabajos de Ivon Le Bot (1976), Francisco Leal (1984), Jaime Caycedo (1984), Álvaro Acevedo (Representaciones, Juventud), Álvaro Acevedo y Gabriel Samacá (Revolución, Juventudes), Manuel Ruiz (2002), Edwin Villamil (2010), Juan Celis (2009), Frank Molano (El imaginario, La izquierda), Mauricio Archila, (El maoísmo, El movimiento), José Díaz, (El movimiento, Juventud, Del liberalismo, El 8 de junio), Jorge Cote (2009).
} 
afectaba a los anhelos de los padres de familia la posibilidad de una carrera revolucionaria que frustrara sus planes de movilidad social depositados en las carreras de sus hijos? ¿Cómo se vivió esto en el comedor y cómo afectó al hogar? ¿Qué consideraciones por su familia habitaban las decisiones de los estudiantes? ¿Cómo vivieron sus vidas emocionales y qué tuvo esto que ver con la militancia? ¿Qué indicios pueden ser sugeridos por respuestas a estas preguntas que permitan comprender más ampliamente las representaciones colectivas y la significación del mundo por parte de los estudiantes? ¿Cómo se mezclaban las ideas políticas con códigos estéticos de vestimenta para generar identidades? La lista es arborescente, pero la idea medular que las atraviesa a todas está orientada por una pregunta principal: ¿qué pasaba con los estudiantes en el detrás de cámaras?, pregunta que se cuestiona precisamente por esas aristas de poca luz. No es este el lugar de responderlas, pero sí el de incentivarlas y realizar aproximaciones.

Creemos que estas preguntas no han sido planteadas formalmente justo por la inexistencia de fuentes que hagan posible responderlas, o solo sospecharlas, pero sobre todo por falta de herramientas para ver nuevos elementos en las fuentes habituales, y nuevas fuentes para pensar los problemas y los actores tradicionales. Un esfuerzo agudo que afrontó el deseo de aproximarnos a los estudiantes de esta manera fue el de encontrar fuentes. ¿Cómo abordarlas, dónde encontrar nuevas evidencias; hay fuentes que no contemplamos como fuentes? Parecía que todo registro provenía únicamente de la actividad política de los estudiantes: estatutos organizativos, semanarios y diarios estudiantiles, además de la prensa nacional y local. Mas no era del todo así: Luis Fayad, un estudiante de sociología de la UN en Bogotá a mediados de 1960, importante figura de la narrativa urbana en la actualidad, escribió una novela titulada Compañeros de viaje (1991) que recrea la vida estudiantil de esa universidad justo en la época en que pasó por allí; y Juan Diego Mejía, un estudiante de matemáticas de la UN sede Medellín a principios de 1970, pero cuya experiencia universitaria y militante estaría ligada a la UdeA, escribió El dedo índice de Mao, novela sobre 
los estudiantes maoístas de esta última universidad. ${ }^{5}$ En estas narraciones se sucedían fotografías en prosa que captaban escenas estudiantiles que, pensándolo bien, no contrastan con las narraciones históricas en donde se ofrecen como calculadores y pasionales izquierdistas, sino las complementan, y a la vez encuentran en ellas un contexto en dónde emplazarse para cobrar más que un brillo estético y literario: un brillo histórico. Se trata de un trabajo colaborativo entre historia y novela, en donde la segunda no solo es un banco de epígrafes, sino todo un sendero lleno de migas de pan. La historia en Colombia no ha encontrado los indicios suficientes en la novela, precisamente porque no ha querido mirarla como una bolsa de indicios.

Fijémonos en lo siguiente: tras la novelística colombiana de la primera mitad del siglo XX, que poseía un tono preferidamente rural, franqueando el hito que sería García Márquez, el realismo mágico y en términos generales el boom, existe un nuevo elenco de autores, como Plinio Apuleyo Mendonza, Héctor Abad Faciolince y Rafael Humberto Moreno Durán, entre varios más, dentro del cual se encuentran Fayad y Mejía, que se caracterizan por hacer parte de una "nueva" narrativa que prefiere los contextos urbanos y que se sitúa en una estética diferente a la tendencia mágico-realista. Con enfoques y conclusiones particulares, hay ya una elaborada y un tanto divergente taxonomía en los estudios literarios, que sitúa a nuestros autores en la Generación Mutante (Mejía), en la Generación del Bloqueo (Peña), o en la del Estado de Sitio (Marín), que sólo mencionaremos para invocar la curiosidad del lector, y de la que resaltamos, una vez más, el elemento urbano persistente y predilecto en esta narrativa.

El hecho que de exista una "nueva" narrativa que prefiera lo urbano, hace, necesariamente, que un elemento significativo del paisaje aparezca en los relatos: se trata de los estudiantes universitarios, y de la Universidad como lugar de significación en donde y a partir de la cual pueden encontrarse y novelarse dramas

\footnotetext{
${ }^{5}$ Nótese que las universidades en cuestión son de carácter público.
} 
que vienen a ser centrales en la constelación de lo urbano, mundo del cual abrevan los autores.

El hecho literario de narrar la vida estudiantil, como lo hacen Fayad y Mejía, se enmarca en un episodio histórico en que los paisajes y la vida urbana cobran vida y mayor vigor en la narrativa nacional. Este hecho literario, que abre una veta probable de estudio, produce un registro que antes no teníamos sobre los estudiantes. Así, por ejemplo, no es posible encontrar en abundancia episodios estudiantiles en las novelas de antes de 1950.

De manera pues que, si nos fijamos en las variables de este fenómeno: presencia de lo urbano en la novela; presencia necesaria de los estudiantes gracias a lo anterior; vida del autor en su contexto histórico que permite una relación con la sociedad que hace posible la escritura de ese tipo de novelas; experiencia política o en todo caso directa, vivencial, en el entorno que luego irán a narrar en sus novelas; bibliografía acerca de los estudiantes en las que es posible emplazar los relatos novelados; y si nos fijamos en las consideraciones breves que haremos sobre algunos elementos de la novela y la historia en los párrafos inmediatamente siguientes, tenemos un conjunto de indicios, premisas y perspectiva, que nos permite entablar un encuentro con el pasado a través de la lectura que hagamos de la evidencia.

Es extraño que la novela no haya sido considerada antes en esta perspectiva, y la detracción de su uso como fuente se queda corta para justificar toda la ausencia de reflexión en este sentido. El titiritero (Álvarez, 1979), Los estandartes rotos un episodio obrero-estudiantil (Corsi, 1973), Los funerales de América (Soto, 1980), La siembra de Camilo (Soto, 1971), Sin remedio (Caballero, 1984), Cartas cruzadas (Jaramillo, 1993 ), o la más reciente Disturbio (Manrique, 2009), y otras varias que se quedan sin nombrar, son una muestra corta de la novelística colombiana que refiere a los estudiantes en sus narraciones, e indican la vigencia del tema en la novela. ¿Son solo ficciones? ¿Tendrá alguna importancia que los autores hayan sido estudiantes universitarios? ¿La experiencia y la memoria de los hombres que escriben ceden todo a las tareas de 
la verosimilitud y de la experiencia estética? ¿Por ser estética deja de ser histórica? ¿Es solo un artilugio bello la persistencia del tema en la novela y sus contrastes y encuentros con la bibliografía sobre el tema? Estas preguntan tendrán eco en algunos lectores que como el autor, ha disfrutado de las novelas sin perder al final de la lectura la sospecha de que no todo era "literario". ¿Cómo seleccionarlo, entonces? ¿Cómo convertir un elemento de la ficción en un indicio? ¿Cómo pensar en la novela como fuente de evidencia histórica? El punto está en leer novelas, y en sistematizar y darle forma a esas intuiciones, para que dejen de serlo y metamorfoseen en argumentos que hagan viable el uso de la novela, ya que el orden de cosas indica que antes de preguntarnos por el conocimiento y por el pasado, habría que presentar nuestras ideas ante el estrado de las comunidades académicas.

Debido al objetivo de este artículo no contamos con espacio para desarrollar en extenso algunas reflexiones a que hemos llegado al respecto del uso de la novela como fuente. ${ }^{6}$ Sin embargo, conviene que el lector tenga en cuenta algunos elementos para la lectura del apartado final: 1. La trayectoria y la memoria de los autores son puntos especialmente importantes, pues funcionan como conector entre los acervos historiográficos y lo narrado en las novelas pensado como indicio o evidencia. 2. Fruto del primero, las novelas que utilizamos poseen un carácter testimonial que si bien no configuran elementos verdaderos en las narraciones, tampoco los configuran falsos, y encargan la responsabilidad de dar sentido a la evidencia y de argumentarla al investigador. 3 . La condición de la información que ofrece la literatura no es igual a la de los folios de un archivo: mientras que la de un archivo puede ser información directa y singular, la de la literatura es indirecta y tipificada, es decir, no remite a sujetos singulares sino que sus referencias a sujetos, acciones o situaciones contenidas en

\footnotetext{
${ }^{6}$ En cualquier caso, al respecto se sugiere al lector la revisión de un artículo nuestro de próxima aparición en la revista Historia Caribe, N28 titulado "La novela como fuente para la historia cultural: ideas para un consenso", en donde se reflexiona sobre la condición de la novela y de la información que esta puede ofrecer y que la hace viable para la investigación histórica de la cultura, usando ejemplos de estas novelas que, por mantener el orden de la argumentación, no hemos agregado.
} 
la figura del personaje, condensan tipos sociales más amplios (este abordaje permite interpretar a los personajes estudiantiles como referencias tipificadas a facciones o conjuntos estudiantiles más amplios y a características estudiantiles más extendidas). 4. La novela puede llegar a ser un informe y los autores nativos informantes de su tiempo: la dificultad del trabajo reside en leer e interpretar esos informes, asumiendo los acertijos de la metáfora y las formas de la ficción sin el (pre) juicio a-histórico de que estas son formas de la mentira. 5. Con otros intereses, como el de historiar las manifestaciones políticas, la novela no sería más que un banco de epígrafes o de sugerencias vaporosas. Su condición la hace útil especialmente para explorar los pensamientos, las emociones, la vida cotidiana, las preocupaciones, los valores, las representaciones: asuntos que empezaron a impórtale a la historia sólo recientemente. 6. Este trabajo es sobre un caso específico y con una muestra determinada de novelas que apuesta por compartir una elaboración a partir de indicios encontrados en obras literarias.

Por último, central en este trabajo, la categoría de representaciones colectivas - a donde confluyen las exploraciones de los escenarios familiarcotidiano-afectivo de los estudiantes- la entendemos en la perspectiva de Roger Chartier. En efecto, las representaciones colectivas son una categoría que expresa la instancia en la cual los seres humanos percibimos y clasificamos las divisiones de la organización social, y a partir de las cuales nos relacionamos con el mundo, de manera que resultan en "matrices de prácticas constructivas del mundo social en sí” (Chartier 56). Según el autor, la noción de representaciones colectivas:

Autoriza a articular, sin duda mejor que el concepto de mentalidad, tres modalidades de la relación con el mundo social: en primer lugar el trabajo de clasificación y desglose que produce las configuraciones intelectuales múltiples por las cuales la realidad está contradictoriamente construida por los distintos grupos que componen una sociedad; en segundo, las prácticas que tienden a hacer reconocer una identidad social, a exhibir una manera propia de ser en el mundo, significar en forma simbólica un status y un rango; tercero, las formas institucionalizadas y objetivadas gracias a las cuales los "representantes" 
(instancias colectivas o individuos singulares) marcan en forma visible y perpetuada la existencia del grupo, de la comunidad o de la clase (56-57).

Es una categoría que permite apreciar la incorporación del mundo social en los esquemas mentales de los grupos y los individuos, así como su incidencia en las prácticas y en las formas institucionalizadas y objetivadas de existencia; es decir: hacen visible el flujo del mundo social a través de los individuos que lo desglosan al tiempo que orientan su ser en él. De manera que importan principalmente tres aspectos. Primero, el trabajo de clasificación y desglose, segundo, las prácticas, tercero, las formas institucionalizadas y objetivadas de los "representantes". Estos asuntos orientaron nuestra interpretación de los datos sobre la familia, lo afectivo y lo cotidiano, hacia una reconstrucción del significado que tuvo el mundo para el actor en cuestión.

Lo familiar, lo cotidiano y lo afectivo, fueron ejes de lectura de las obras: elementos que persistían en ambas novelas y que permitían, primero, esquematizar los dos momentos en un hilo narrativo y, segundo, acceder de manera confidencial a los estudiantes. A continuación, la primera parte está dedicada a contextualizar las narraciones noveladas y la segunda a la reconstrucción histórica. Es necesario realizar esta contextualización con cierta amplitud, para que el lector encuentre la manera como se emplazan las narraciones.

\section{Los estudiantes de 1965 en Bogotá y de 1970 en Medellín. ¡Cámaras, luz, acción!}

Como hemos dicho, Fayad y Mejía fueron estudiantes universitarios durante los años en que son recreadas sus narraciones. Fayad en la UN en Bogotá por los años de 1965, y Mejía en la UN en Medellín (sede) a principios de la década de 1970. Esto nos permite sugerir que el contenido narrado de las novelas no es sólo fruto de la creación imaginativa, sino que está ligado a la trayectoria y a la experiencia inscrita en la memoria. Además, si tenemos en cuenta que ambos 
mantienen vínculo con el medio universitario de la actualidad (Mejía en la UN en Bogotá y Fayad en distintas universidades alemanas) podemos sugerir que gracias a sus experiencias de contacto, y partir de la observación de las diferencias de los estudiantes contemporáneos con aquellos que compartieron el claustro educativo con ellos, las particularidades del medio estudiantil de mediados de 1960 y principios 1970 se hacen más vívidas para sus memorias (debido a la diferenciación) y por tanto mejor recreadas, matizadas o detalladas (recordemos que la novela de Fayad se publica en 1993 y la de Mejía en 2003).

Para proceder metodológicamente, así como los estudiantes de 1960 y 1970 pueden ser diferenciados respecto de los actuales ${ }^{7}$, pueden diferenciarse también de los estudiantes de décadas precedentes. Esta distinción permite, primero, dar cuenta de las propiedades y particularidades de los estudiantes y, segundo, contextualizar el tipo de estudiante que existió en los dos momentos (mediados del 60, principios del 70) con el fin de generar una imagen situada del estudiante en la novela a partir de una referencia diacrónica.

Durante el decenio de 1950 en Bogotá, a diferencia de la índole de las preocupaciones y debates estudiantiles de mediados de 1960, estos estuvieron adscritos a los partidos tradicionales y replicaron sus discusiones al interior de la universidad (Ruiz 57). Ello sucedía porque los estudiantes provenían de las clases económicas más pudientes y sus familias, que por aquella época cumplían un papel central en la trasmisión de la tradición (Melo), se adscribían a los partidos políticos conservador y liberal. Pero para 1965, después de que el escenario estudiantil mudara hacia las causas ahora gremiales o las combinara, tal como sugiere Ruiz Montealegre, los estudiantes “encontraron unas condiciones más favorables en términos gremiales y de bienestar, lo cual influyó para que las

\footnotetext{
${ }^{7}$ En términos de la diferencia de los ambientes políticos y culturales a los que pertenecen. Un ejemplo de esta diferencia es la asiduidad lectora de los estudiantes del pasado frente a los contemporáneos, enfrentados no ya al surgimiento reciente de los medios de comunicación masiva en nuestro país sino a un momento en que los medios se han consolidado, y la cultura política y las prácticas de lectura se ven inmersas en el capitalismo moderno que ciertamente las transforma, en relación, reiteramos, con la amplia y dedicada formación de los estudiantes de antaño.
} 
luchas de carácter reivindicativo cedieran su lugar de principales motivaciones estudiantiles, a los planteamientos políticos revolucionarios" (Ruiz 218).

Dichas condiciones más favorables a las que se refiere el autor, son relacionadas directamente con factores organizacionales, pero creemos que además de causas internas existieron otras externas como algunas situaciones y acontecimientos políticos nacionales e internacionales en los que se puede ahondar para explicar ese nuevo panorama. En el orden nacional, la primera parte de la década del 50 estuvo signada por el retorno del conservatismo al poder (Laureano Gómez: 1950-1951; Urdaneta Arbeláez: 1951-1953), lo que significó “el retroceso en la modernización de la educación superior" (Ruiz 58$)^{8}$ y que a la postre resultaría en una creciente atención del estudiantado en intereses de orden gremial. Posteriormente la segunda parte del decenio de 1950 estuvo marcada por la dictadura de Rojas Pinilla (1953-1957), que además de proponerse desarticular cualquier posibilidad de movimiento estudiantil (Ruiz 59), generó un sentimiento antimilitarista entre los estudiantes debido a los trágicos sucesos de $1954^{9}$. Esto generó una huella de inconformidad aguda entre los estudiantes que sería apaciguada en los primeros años de la década de 1960 por la atmosfera de convivencia que generó el establecimiento del Frente Nacional (1958-1974) ${ }^{10}$, pero que se desvaneció pocos años después. Y tuvo que ser así porque además del

\footnotetext{
${ }^{8}$ El autor menciona que ello sucedió como efecto de los decretos 3708 de 1950 y 0063 de 1952 que dieron marcha a la ley 68 de 1936 "eliminando parcialmente la autonomía que había alcanzado la Universidad Nacional".

9 "Estudiantes de varias universidades de Bogotá participaron en un desfile hacia el cementerio para conmemorar los 25 años de los acontecimientos de 1929 [muerte el estudiante Gonzalo Bravo Pérez a manos de la policía]. En la tarde, en predios de la Universidad Nacional, fue asesinado por la policía el estudiante de Medicina Uriel Gutiérrez. El hecho conmovió profundamente al estudiantado de la capital, que al día siguiente, en señal de duelo y protesta, organizó una marcha hacia el Palacio de Gobierno. A la altura de la calle 13 con carrera séptima la manifestación fue interrumpida por las otras del Batallón Colombia, que recientemente había participado en la guerra de Corea. En hechos nunca esclarecidos por la justicia ordinaria, el ejército abrió fuego contra la manifestación, produciendo un número no determinado de muertos, aunque las versiones apuntan alrededor de diez estudiantes asesinados" (Ruiz, 2002: 55-56).

10 Se conoce como Frente Nacional en Colombia al pacto bipartidista (partido conservador y liberal) que dio lugar a 16 años de gobierno turnado entre los partidos conservador y liberal por periodos de cuatro años. Se resalta con fines explicativos que este pacto tuvo la consecuencia, entre otras, de generar una atmosfera tensa de inconformismo debido a la obstrucción de la participación política que significó.
} 
desencantamiento político frentenacionalista de los estudiantes, en los años 50 se inició un proceso de masificación de los medios de comunicación que, finalizando el decenio, prestaría el soporte necesario para que la influencia que recaía sobre el pensamiento estudiantil proviniera de fuera del territorio nacional, y fuera leída en la prensa y escuchada en la radio, por ejemplo, la entrada a la Habana el 8 de enero de 1959 de los revolucionarios cubanos. Además por el posterior flujo creciente de bibliografía crítica nacional y extranjera que circuló en el medio de autores como Louis Althusser, Simone de Beauvoir, o los imprescindibles de Marx, Lenin y Mao.

De entre los sucesos de orden internacional que influyeron en ese proceso de cambio, la Revolución Cubana es el más significativo por cuanto devolvió a la escena mundial la idea de la vigencia de la opción armada como "posibilidad real de provocar cambios sociales" (Díaz, Juventud 266), y para los grupos disidentes en América Latina generó un nuevo aire que se conoce como la Nueva Izquierda, materializado en Colombia principalmente en el MOEC 7 de enero (Díaz, El movimiento), cuyos integrantes, como sugiere J. Díaz en el caso de Antonio Larrota $^{11}$, expresan los avatares políticos de una generación de jóvenes animados por la revolución ${ }^{12}$.

\footnotetext{
${ }^{11}$ El artículo del profesor Díaz (Juventud) es un ejemplo puntual sobre un personaje-ventana que nos permite observar las dinámicas y exigencias del momento histórico a través suyo. Tras la Revolución Cubana varios integrantes del MOEC viajaron allí a recibir formación política y militar. En cinco ocasiones diferentes intentaron crear focos armados. Las cinco fueron fallidas y en una de ellas murió Antonio Larrota González, su principal líder. A través de Larrota, Díaz observa el carácter histórico de los estudiantes que, en los sesentas y setentas, entendieron el tiempo que habitaron como un reto, a través del cual era posible atraer un futuro de cambios sociales tangibles. Debido a la expectativa de un futuro mejor, elaboraron un presente que les permitiera atraerlo. Construyeron prácticas que lo hicieran posible. Una de ellas fue el abstencionismo en la urnas, otra la preferencia por la lucha armada como mecanismo de lograr los cambios sociales, y otra más, el voluntarismo político, que les llevó a pensar con obstinación que las condiciones objetivas para la revolución en Colombia estaban dadas. Son solo tres rasgos, dentro de una gama amplia de comportamientos e ideas, que esperan despertar la curiosidad del lector para que amplié sus lecturas al respecto.

${ }^{12}$ Pensando en la relación entre la Revolución Cubana y los estudiantes colombianos, hacen falta estudios que den cuenta de la influencia de la Revolución en términos culturales. Muy poco se sabe, por ejemplo, de la "apropiación" cultural que hicieron los estudiantes de las prácticas y modelos puestos en escena por los rebeldes cubanos, y más bien se ha permitido fácilmente pensar que las actuaciones armadas en nuestro medio fueron simples réplicas de la experiencia cubana, sin reparar en las dimensiones de la apropiación cultural.
} 
En síntesis, en el transcurso de los años 50-60, los intereses de los estudiantes, sus preocupaciones y debates, migraron paulatinamente su atención de acuerdo a la situación política nacional e internacional de una réplica partidista en el escenario universitario, pasando por la posterior preocupación de los intereses gremiales del grupo estudiantil, hacia la integración de la situación social, política y cultural del país en sus agendas de reflexión, prácticas y expresiones políticas ya al final de los años 60. Pero los estudiantes de mediados de esta década no sólo encontraron un ambiente favorable en términos gremiales y de bienestar ${ }^{13}$, sino que además, y sobre todo, encontraron un camino allanado que apuntaba hacia la radicalización y que en adelante estaría ambientado por la ideas de izquierda. Fue en ese contexto que Fayad estudió sociología en la UN en Bogotá, el mismo contexto que campea en su novela y que, si pensamos en él al momento de leerla, encontraremos una narración emplazada en la época cuyas descripciones poseen no solo gran correspondencia entre sí, sino que permiten sugerir, de hecho, algunas escenas que no observamos en los trabajos académicos.

Ahora bien, si para mediados del 60 los medios de comunicación permitían un cierto flujo de influencias sobre los estudiantes, para los primeros años de la década siguiente estos se habrían consolidado aún más (al tiempo que la oleada de bibliografía crecía) y permitían a los estudiantes estar más pendientes de los sucesos internacionales. Esto sucedía por las condiciones objetivas de existencia más sólida de los medios de comunicación en el territorio nacional, pero sobre todo, era así porque para los estudiantes de entre 1965-1972, alejados ya del parroquialismo político, el acontecer mundial cobraba una relevancia mayor.

La nueva izquierda se entiende como el

${ }^{13}$ Da la impresión de que esta idea de Ruiz Montealegre resuelve la tendencia estudiantil a organizarse sugiriendo implícitamente que es una acción espontánea, y no un síntoma del malestar social por el cual se vieron abocados a buscar soluciones, o un resultado de las influencias del medio y de las apropiaciones, para nada pasivas, de este. 
intento de renovar el ideal revolucionario en los años 60 por parte de grupos y organizaciones al margen de los viejos partidos obreros socialistas y comunistas (...) [que] se caracterizó además por su adhesión a la lucha armada como la principal forma de acción revolucionaria, así no siempre se llevara a la práctica. (Archila, El maoísmo 150)

Y si bien esta surgió en el ambiente sísmico internacional de la izquierda a finales del 50 y mina las mentes estudiantiles durante la década siguiente, para los años 70 se habría generalizado aún más en el medio estudiantil nacional y era generadora tanto de los debates internos (los que propendían por las armas y los que bogaban por soluciones de negociación) como configuradora de identidades estudiantiles en tanto funcionaba como la directriz de las prácticas que los estudiantes debían desplegar para desarrollar la revolución, de manera que contribuyó a configurar las representaciones estudiantiles por las cuales unos grupos se identifican como diferentes o antagónicos de otros, que para el caso se dividían entre los pro-armados y los que creían en las salidas negociadas, los cuales siempre trataron de descalificarse mutuamente.

Hacen falta estudios que expliquen las causas de la repartición ideológica de la ideas de izquierda en el territorio nacional. Sería de ayuda comprender, por ejemplo, por qué el maoísmo se asentó fuertemente en Medellín y no en otras regiones. No obstante, es posible alguna caracterización de los estudiantes de Medellín de los primeros años del 70.

Partamos de que la novela de Mejía se ocupa principalmente de los estudiantes maoístas en Medellín por encima de cualquier otro grupo estudiantil. Allí hay una primera correspondencia entre la narración novelada y la historia de los estudiantes, relacionada con el protagonismo de ese sector. Sin embargo, aclaramos esto sobre todo para indicar que los estudiantes sobre los cuales pondremos nuestra atención en el caso de esta novela serán aquellos de filiación maoísta. Ahora bien, aunque Mejía estudió en la UN de Medellín, su novela se ambienta en la UdeA, lo cual, al contrario de hacer perder la relación histórica, la 
intensifica en el sentido en que la acción estudiantil de aquellos años se concentró en esa universidad como lo sugieren las palabras del autor:

La historia de El dedo índice de Mao es una historia que a mí me gusta bastante porque habla de mi hermano; es un poco basada en mi hermano que es retardado mental, y mis primeros años en la universidad cuando yo quería meterme en la revolución. Entonces cuenta la vida universitaria en la Universidad de Antioquia. A pesar de que yo estudié en la Nacional (sede Medellín) ese libro se desarrolla es en la Universidad de Antioquia. Porque yo pasaba mucho tiempo en la de Antioquia. La Nacional y la de Antioquia en Medellín quedan a dos kilómetros de distancia, quedan muy cerquita, entonces en la década del setenta toda la actividad revolucionaria de la universidades públicas y privadas se centralizaba en la Universidad de Antioquia. Allá llegábamos estudiantes de todas las universidades. Eso era una fiesta; era una cosa hermosa: ver a las niñas de las universidades públicas, de las universidades privadas, todas participando en las asambleas, en los mítines. A mí me quedó grabado mucho la imagen esa, como esa confluencia de colores, de rostros. ${ }^{14}$

A todas luces, la década del 60 fue un período de radicalización estudiantil, y si bien en el lapso de 1950 a 1965 sus intereses migraron de foco (centrándose en el país político al final de esos quince años), para los primeros del decenio de 1970 el escenario habría llegado al punto en que las ideas de izquierda se ofrecían paradigmáticas para el grueso del estudiantado comprometido. Por supuesto que permaneció siempre una facción de estudiantes no participantes, pero al interior de los estudiantes que nos interesan las ideas de izquierda daban para alimentar todas las discusiones, tanto en lo relativo a solucionar tendencias y actitudes frente al establecimiento como en lo concerniente a tomar posiciones al

\footnotetext{
14 Entrevista a Mejía, Juan Diego, realizada por León. I.R, [Geniusapiens], Bogotá, abril 4 de 2010. https://www.youtube.com/watch?v=wL4GkTI5Un0 (mayo 10 de 2012).
} 
interior de los grupos en relación con los demás bandos que conformaron el panorama estudiantil, e incluso para enjuiciar o alabar los comportamientos de los integrantes del mismo bando. Y no pudo ser de otra manera, porque durante la década de 1960 se alentó en tal medida la idea de poder realizar cambios sociales mediante la revolución, que las generaciones de estudiantes de esta década y la siguiente, al igual que el grueso de la intelectualidad crítica no sólo del país sino de América Latina, tuvieron la certeza de que una transformación radical se gestaba en el momento (Gilman), y ante la cual debían responder con vivacidad.

Con todo, durante los primeros años de la década de 1970 el establecimiento incrementó las medidas represoras de manera directamente proporcional al creciente radicalismo de los estudiantes, y así como "entre 1970 y 1972 fueron más frecuentes las grandes concentraciones de estudiantes en la plazoletas centrales y teatros universitarios" (Villamil 236) con fuerza similar el gobierno (en el poder se encontraba el conservador Misael Pastrana Borrero) arremetió contra los estudiantes, incluso tratando de ponerle en contra del ciudadano común (239), además, por supuesto, de los medios violentos ejercidos como las ocupaciones militares de los claustros universitarios o el brusco aplacamiento de la protesta. Desde el principio, la década de 1970 comenzó siendo una década agitada y es prueba de ello el hecho de que inició con el mítico paro estudiantil de 1971 y con un estado de sitio relacionado también con sucesos estudiantiles. Ocurrió también que la fuerte visibilidad que los estudiantes habían logrado hacia finales de los años 50 (Cote 413) se mantuvo, pero con el añadido que generó el desencantamiento político generalizado que produjo el Frente Nacional entre los diferentes sectores sociales, entre ellos los docentes que, como asegura Villamil citando a LeBot, durante esos conflictos prolongados brindaron su apoyo a los estudiantes (Villamil 238).

Los universitarios estuvieron a la orden del día durante aquella década, cumplieron un rol protagónico en una sociedad que también por aquel momento tenía los ojos puestos en ellos, y al calor de la experiencia política internacional fraguaron sus diferentes expresiones políticas y filiaciones ideológicas, como la 
del maoísmo, por ejemplo. Ese es el contexto general en el que se ubica el contenido de la novela narrada por Mejía, donde los Maoístas de los primeros años de la década de 1970 en Medellín, específicamente en la UdeA, vuelven a respirar para que podamos recordarlos.

En contraste con lo que ha sugerido M. Archila y F. Molano respecto de los orígenes del maoísmo en Colombia, Hernández Ortiz ha contrastado sus tesis con razón expresando que los

Orígenes del Maoísmo en Colombia [se ubican] en los albores de la década del 50, en forma del pensamiento de Mao Tsé-Tung, el cual se expresó en la experiencia de autodefensa y lucha guerrillera durante los años 1949 y 1958, en la región del Davis, Tolima (Hernández 77-87).

Pero ciertamente es al fragor de la experiencia internacional de finales de 1950 y comienzos de 1960 que la Izquierda comunista sufre una inflexión que será irreversible, materializada en la disputa chino-soviética entre revolución y reforma que dará origen, de la mano con los ecos de la Revolución Cubana, a la nueva izquierda en Colombia, cuya expresión, a su vez y entre otras, se encuentra en el maoísmo estudiantil de la década de 1970. Aquellos estudiantes, por el momento en que Mao aún estaba vivo y la "galería de héroes del imaginario internacional" (Archila, El maoísmo 152) permanecía de pie, vivieron sin duda una de las experiencias más intensas de la izquierda en nuestro país. Plegados a la discordia chino-soviética consumieron aquellas iras y produjeron las propias en el escenario universitario. Pero también como sector heterogéneo presentaban divergencias; este es el caso de los dos polos que según M. Archila conformaban el maoísmo: uno representado por el "campo M-L" [marxista-leninista], "que abarca a todas las organizaciones que tuvieron que ver directamente $\mathrm{o}$ indirectamente con el partido comunista marxista leninista (PC-ML), y se caracterizaron, al menos hasta los años ochenta, por una rígida ortodoxia maoísta”, y el otro personificado por el MOIR “que representa una visión más 
heterodoxa" en donde primaba lo político sobre lo militar, a diferencia del "campo M-L” (148). Esa discordia heredada que los estudiantes maoístas vivieron los hizo diferenciables del resto de los grupos estudiantiles. Lejos de sugerir que los estudiantes no maoístas vivían en absoluta armonía unos y otros, se trata de apreciar que para los maoístas existió de manera explícita un "otro" antagónico interno además de las clases dominantes. Esto los hace particulares porque de entrada señala que no solamente su ser revolucionario se desarrolló en contra de las oligarquías sino que además tuvieron que desplegarse contra los "revisionistas", apelativo que recaía sobre quienes consideraban como militantes que bogaban por las medianas soluciones, negociadas con una eventual burguesía nacional.

Los maoístas reivindicaban "la lucha armada en la modalidad de guerra popular prolongada como se vivió en la experiencia china" (168), de manera que para ellos la figura central para realizar la revolución no eran los obreros sino los campesinos, y por ello se explica la importancia de "irse al campo" a realizar las tareas de la revolución, asunto que se vivió entre los estudiantes maoístas de la UdeA, quienes como se ha sugerido, abandonaron los intereses individuales en pro del beneficio común y entregaron sus vidas a la causa. De otra parte, fue tal el fervor del momento que los estudiantes rayaron en el dogmatismo, teniendo el dogmatismo maoísta

una particularidad con relación al resto de la izquierda, y es que se aferraba a un 'pensamiento' y en últimas a una figura carismática, hasta caer casi en la veneración religiosa de Mao. Ya no era solamente el 'culto a la personalidad' practicada por el estalinismo, sino una actitud de fe en el 'Gran Timonel (170).

Este dogmatismo también los llevo a recrear lo que M. Archila denominó un 'voluntarismo subjetivista', según el cual los estudiantes tendían a alejarse de todo lo que les obstaculizara el camino, como las llamadas condiciones objetivas 
(171). Así mismo, para ellos los principios eran fundamentales. Destaca el rigor con que afrontaron la situación, "la moral espartana de sacrificio material y afectivo" como lo denominó el autor en mención. La "igualdad proletarizante" también es otro rasgo que sobresale, según el cual todos debían acercarse al pueblo despojándose de los gustos burgueses. De la misma manera despunta la propensión a la clandestinidad y a la conspiración en el maoísmo (sobre todo en el campo M-L) como uno de sus rasgos más característicos en Colombia (181).

Por último, quisiéramos señalar que los estudiantes maoístas de principios de la década de 1970 debieron haberse sentido como un grupo atacado dentro de la izquierda por aquellos que consideraban como los traidores internos: los 'revisionistas'. Según la relación entre establecidos y marginados que plantea N. Elias existe un nosotros (79-138) al que se adscriben los individuos de cada grupo. Al respecto queremos señalar que si interpretamos a los maoístas desde esta perspectiva podemos sugerir que las acciones desarrolladas por ellos para corregir las conductas de los integrantes del grupo que se relacionaban con otros integrantes de otros grupos no sólo eran acciones de castigo y corrección que muchas veces llegaron al punto del asesinato, sino que estaban orientadas por un profundo sentimiento de defensa del nosotros que se sentía atacado directamente no sólo por la oligarquía sino por quienes representaron hasta hacía poco sus antiguos aliados. En todo caso, si hubiera la posibilidad de que los grupos de izquierda del entonces, por heterogéneos que fueran, se concibieran con un nosotros más amplio, la experiencia de vivir el nosotros debió resultar en sumo desoladora y desconfiada, y quizá también por ello el alto grado de clandestinidad.

Hasta ahora, hicimos referencia a un grado de inteligibilidad que abreva de la tradición historiográfica de la cuestión estudiantil centrado en las características del medio político y de su incidencia en los estudiantes universitarios, así como una breve semblanza de sus rasgos. Ahora bien, con el propósito de aportar más elementos para el estudio de este sujeto, apuntando quizá a una faceta más terrenal, las siguientes líneas se encargan de revisarlos en la novela. 


\section{¡Corte, se graba, tomen un descanso! Lo familiar, lo cotidiano, lo afectivo y las representaciones ${ }^{15}$}

El orden del subtítulo está dado por el orden de las novelas y por la cronología estudiantil. La cuestión familiar es vívida en ambas novelas. Lo cotidiano está presente en las dos pero resulta más sugerente y paisajístico en la de Fayad. Lo afectivo se encuentra en ambas novelas aunque matizado por los diferentes momentos y lugares. Las representaciones no son tan explícitas en la obra de Fayad como en la de Mejía. Por ello proseguimos abordando cada asunto protagónico primero desde la novela de Fayad, que recrea mediados de 1960 en Bogotá, continuando cada uno con nuestra interpretación de la información de la novela de Mejía, que se encarga de los primeros años de 1970 en Medellín. Con esto además queremos indicar implícitamente nuestra invitación a observar la recurrencia de la vida íntima estudiantil en las novelas y su valor como fuente, que en tanto narraciones han sabido sospechar más agudamente que la Historia.

Hacia mediados de 1960 en Bogotá la familia había perdido el rol central como transmisora de la tradición, pero ciertamente representaba parte de la escena privada de los estudiantes donde se replicaban los debates universitarios, con la particular disposición de que allí se vinculaban con preocupaciones domésticas y, como núcleo social, sufría el impacto de la cuestión estudiantil toda vez que las ideas de la juventud ponían en riesgo el sueño de movilidad social o fracturaban la cotidianidad del hogar. Fue común el sentimiento de que las actividades políticas de los hijos ponían en peligro el trabajo desarrollado por los padres para ascender

\footnotetext{
${ }^{15} \mathrm{El}$ análisis que se ofrece en este apartado fue construido a partir de los indicios que ofreció la información tipificada en la novela, asumiendo con juicio selectivo que tanto personajes, acciones y situaciones (no todas) hacen referencia a conjuntos de sujetos, acciones y situaciones más amplios, es decir, a tipos más densos. Alentamos al lector a consultar las novelas en cuestión y a pensar su relación con el momento histórico (el narrado como el de enunciación) así como con la bibliografía sobre el tema estudiantil, para discutir con agudeza nuestra propuesta, antes que recusar el uso de la novela en favor de planteamientos teóricos que son productos de reflexionar sobre novelas de otras latitudes y sobre historias de otras latitudes.
} 
socialmente, siempre que la causa política aparecía como causante de renuncia a los estudios o como distractor ${ }^{16}$. Los padres proyectaban en sus hijos lo que deseaban haber sido y fue una constante el sentimiento de orgullo al tener un hijo matriculado en Derecho o Medicina en la UN, así como fue una constante el sentimiento de riesgo del patrimonio familiar con la aparición no de un universitario en casa sino de un militante. También existió un miedo recurrente en los padres respecto del peligro que corrían sus hijos vinculados a la política, y no faltó la situación de que ante el anuncio radial de un estudiante muerto la familia se reuniera angustiada en la sala a esperar o se movilizara a las estaciones de policía tras los constantes enfrentamientos con la fuerza pública. En síntesis, durante mediados de la década de 1960, en la que emergía la clase media, las familias en cuyo seno había un universitario manifestaron en la escena privada el momento político que vivía un país en que los estudiantes eran protagonistas en la esfera pública.

Pero en la familia no todas las situaciones fueron conflictivas. Para 1965, apenas 17 años después del Bogotazo, las ideas disidentes no representaban de manera generalizada una ruptura con la idiosincrasia de los padres, pues muchos de ellos habían participado del gaitanismo ${ }^{17}$, por ejemplo, y las ideas de sus hijos

\footnotetext{
${ }^{16}$ Una de las bondades de la novela consiste en que gracias a que el autor buscar darle significación, tensión y contexto a las acciones y pensamientos de sus personajes, entonces recurre a diversos escenarios en donde su personaje se defina en razón de la manera como resuelve las diversas situaciones que se le presentan. Estos escenarios que el autor plantea no estarían únicamente diseñados a partir de una pretendida imaginación a-histórica (como si eso fuese posible) ni con el propósito exclusivo de construir la verosimilitud de su relato. Allí interviene tanto la memoria como el trabajo de búsqueda que también despliegan los escritores de novelas, y sin duda el psicoanálisis podría dar más luces sobre la deconstrucción histórica que pueda hacerse de los argumentos de novelas a partir del estudio de la persona que las escribe. Entre tanto, la idea sobre la que está puesto este pie de página, se origina en las referencias familiares de la obra: la familia de Amadeo, personaje principal y estudiante de derecho; la de Manuel, su primo y estudiante de medicina; la de Irma, su pretendida; la de los hermanos Gómez (muy allegados a la familia de Amadeo y junto a quienes se escenifican varias situaciones familiares relacionadas con la vida política de los estudiantes) permiten observar el encuentro entre la vida política de los estudiantes y sus vidas domésticas, así como los conflictos entre estos dos escenarios.

${ }^{17}$ El gaitanismo fue un movimiento popular encabezado por Jorge Eliecer Gaitán Ayala. En términos generales, bajo la rúbrica de gaitanista y/o gaitanismo, convergían multitudes de colombianos y colombianas, en su mayoría de clase baja y media, que por su carácter de líder carismático, gran orador y fuerte formación política y compromiso social (además, por supuesto del carácter populista de su manera de hacer política) encontraban en él a un líder que representaba
} 
ahora cercanos a la izquierda terminaban siendo una especie de continuidad ideológica agudizada o radicalizada. Estas familias vivieron una cotidianidad un tanto diferente en el hogar. Del mismo modo que las familias lejanas a la disidencia éstas sentían miedo cuando sus hijos tardaban en llegar a casa después de los enfrentamientos con la fuerza pública, pero a diferencia de aquellas, no generaron la misma resistencia a la participación política estudiantil, ni encontraron truncados sus sueños de movilidad social con la misma gravedad, pues seguramente guardaban cierta complicidad con las ideas de sus hijos, y al contrario de ejercer coerción en este sentido ofrecían incluso su apoyo, que ya sea moral o material ${ }^{18}$, hace visible el tránsito de efectos de lo privado a lo público.

El dedo índice nos remite a otra situación familiar. En el Medellín de los primeros años del 70, los estudiantes maoístas estuvieron no sólo expuestos a las lides políticas de la escena pública sino a la confrontación interna proveniente del contrapeso entre los roles familiares y la militancia. Este es el dilema del protagonista a través de la novela. La familia exigía un desempeño de cada miembro que promoviera la estabilidad o el progreso del núcleo y se sustentaba en correspondencias y obligaciones morales de parentesco, lo que se volvía conflictivo porque la moral maoísta implicaba desprendimiento de la vida familiar, y antes que decidir replicar cualquier experiencia política los maoístas se vieron abocados a un complejo problema individual de decisión. Mencionarlo recuerda que, por su filiación ideológica, los estudiantes también vivieron hondos conflictos emocionales en la escena íntima e individual. La manera de resolver esta situación acarreaba diferentes consecuencias. Al igual que el protagonista, quienes decidieron Familia a militancia, conciliaron cierta tranquilidad encontrándose haciendo lo correcto en relación con las correspondencias y

fielmente sus intereses. Tras la muerte del caudillo, el 9 de abril de 1948, se desató el Bogotazo, acontecimiento que sacudió a todo el país y tras el cual aún nos encontramos en conflicto político y armado.

${ }^{18}$ La obra de Fayad sugiere un tipo de estudiante (condensado en la figura de Eduardo Escobar y madre) que tenía estas condiciones familiares, y refiere una acción de la madre donde ofrece su apoyo para sacar a un estudiante que pudiera estar en apuros en la cárcel a raíz de un enfrentamiento con la policía. 
obligaciones mencionadas (así termina la novela). Para quienes decidieron Militancia renunciando a sus familias, la 'tranquilidad' por hacer lo correcto cobraba una dimensión trascendental por cuanto implicaba sacrifico y abandono, pero esto pertenece más a las representaciones. Antes veamos las notas de lo cotidiano y lo afectivo.

Ciertamente, el asunto político particularizó la vida estudiantil tanto en Bogotá como en Medellín durante los años declarados, pero los objetivos políticos no fueron nunca el único fin perseguido por los estudiantes ni tampoco el único medio que incentivara la militancia. Por el contrario, la vinculación de los estudiantes a ideologías y prácticas de izquierda y los objetivos personales que imprimieron a la militancia presentan una variedad mayor que acude tanto a su condición de jóvenes como a la necesidad de sociabilizar dentro del medio universitario, así como a sus sentimientos e ideas entre otros motivos.

La cotidianidad de los estudiantes de la UN a mediados de 1960 en Bogotá y de la UdeA a principios de 1970 en Medellín transcurrió teniendo como telón de fondo lo político, que ofrecía un marco de encuentro estudiantil, una atmosfera dentro de la que ocurría la vida, pero que no siempre fue ni una directriz ni un fin último absolutos para la vida social estudiantil. Lo político más bien se extendía sobre ellos de una manera que lo permeaba todo sin ser obligadamente una causa omnipresente. Era, como se ha dicho, el marco de encuentro estudiantil en el que se desarrollaba la vida. La condición del estudiante en ese tiempo llevaba una connotación política y era que el momento histórico así lo exigía desde los acontecimientos públicos hasta los más personales como viajar en autobús, pues aún dentro del vehículo, rumbo a cualquier destino, la radio estaba constantemente haciendo alusión a la cuestión estudiantil y era el pan diario de la conversaciones de la gente del común. Esa vida incluía los paseos desde las viviendas hasta la universidad donde se recreaban tanto las inquietudes políticas como las situaciones afectivas, por ejemplo. De igual manera la vida estudiantil transcurría en el círculo de los cafés aledaños a la universidad, donde se reunían y conversaban las más de las veces sobre asuntos gremiales o sociales. 
La cuestión está en poder observar más por debajo de la superficie política. Bajo ese manto tenían lugar preocupaciones terrenales. El diario a diario acontecía entre reuniones al interior de la universidad, mítines, asambleas y protestas, pero esas son palabras que evocan lo político de una manera absoluta. En ese acontecer, mientras los estudiantes preparaban pancartas para manifestarse, escuchaban al interlocutor o comentaban entre sí en lo que duraba una asamblea, tenía lugar la interacción social. Así sucedió en los dos momentos estudiantiles. Los estudiantes exhibían el manejo del discurso de la ideología que habían apropiado, pero ello no siempre ocurría con el fin de alentar o formar a las masas, a veces simplemente ocurría para señalar superioridad frente a otro grupo o frente a un integrante del mismo bando. Aquellas rencillas tenían motivos frecuentemente bastante disimiles del político nacional, y fue habitual que sucedieran, por ejemplo, como una muestra de rechazo a la identidad de los otros grupos, como lo demuestra la narración de El dedo índice, o para agradar a alguna chica mediante el manejo de la retórica, como lo sugieren ambas narraciones.

De cualquier modo, la relación entre estudiantes-Estado ha orientado los acercamientos académicos generando importantes avances sobre la comprensión del pasado estudiantil, pero estos avances, por fortuna, evidencian tanto como lo que ocultan. Dentro de ese ocultamiento se encuentran las causas de la militancia que exceden lo político, asunto que conecta esta breve semblanza de lo cotidiano con el asunto afectivo de la vida estudiantil. No sólo en las novelas Compañeros de viaje y El dedo índice de Mao existe el motivo frecuente de los móviles no políticos por los cuales se realizaba la militancia, sino que en otras obras como Sin remedio y Cartas cruzadas también hace parte del argumento, aunque desde perspectivas bien marcadas en relación al grado de aceptación que tienen las ideas de izquierda entre los escritores. Lo afectivo estuvo presente dentro de los estudiantes de izquierda, hizo parte de las prácticas cotidianas aparentemente vinculadas sólo a motivos políticos, y en no pocas ocasiones incentivó la militancia. Para mediados de 1960 en la UN en Bogotá este motivo estuvo presente en las organizaciones e impactó las prácticas de los integrantes. Fue 
común que no sólo por convicción los estudiantes participaran de las acciones de protesta, sino que en repetidas ocasiones sus actuaciones servían para despertar el interés en alguna mujer del grupo, o viceversa. Ello implicaba una cierta teatralización de la acción de protesta encaminada en esa dirección: algunos estudiantes participaban con arrojo y esperaban ser observados y congratulados y si sufrían alguna leve lesión, una raspadura, o en todo caso una huella que recordara su participación, era frecuente que pensaran que esto incentivaría a las mujeres para que se fijaran en ellos, y si bien no obtenían en todos los casos la respuesta deseada, esto indica que tal percepción del género femenino hacia parte de las representaciones colectivas de los estudiantes masculinos al interior de los grupos.

Durante los primeros años de 1970, en la UdeA la situación presentó el mismo esquema, pero con las particularidades del escenario estudiantil maoísta. En la novela de Mejía se sugiere con mayor intensidad el motivo afectivo como generador de militancia. Fue frecuente que la participación en reuniones, asambleas o mítines se realizará no sólo por convicción política sino por interés personal en algún integrante, y sin duda ese motivo engrosó las filas de las organizaciones. Por lo mismo, si en algún momento menguaba la disciplina de la militancia, el componente emocional podía ser suficiente para reactivarla. Una vez realizados los vínculos emocionales, las prácticas estudiantiles de disidencia como salir en las noches a pintar muros o entregar volantes políticos a la entrada de las fábricas- adquirían un tinte más íntimo y emocionante toda vez que realizarlas en compañía de la pareja estrechaba los lazos de unión y significaba el riesgo de ser reprimido y apresado por la fuerza pública. De igual manera, al interior del maoísmo de la UdeA el elemento afectivo no sólo tuvo estas implicaciones dentro de los grupos estudiantiles, sino que en ocasiones excedió el escenario universitario. Sucedió que el sueño de la revolución también se vivió en pareja $\mathrm{y}$ fue frecuente que uno de los dos sintiera primero el llamado a encaminarse hacia el monte para tomar las armas y el otro le siguiera, tanto por convicción política pero también por un fuerte vínculo emocional. De igual 
manera que lo cotidiano nos indujo a lo afectivo, este nos devuelve al primero en relación con la toma de decisión de vincularse a la lucha armada, pero antes quisiera invitar a considerar en síntesis que la izquierda y el momento político de estas épocas generaron un despliegue emocional y permearon no sólo la vida pública sino también la privada, produciendo nuevas maneras de experimentar la interacción social, de vivir en sociedad y de significar el mundo que están aún por ser investigadas.

Durante los primeros años de 1970 el diario a diario de los estudiantes maoístas de la UdeA estuvo inmerso en la atmosfera colectiva que circundaba la acción de irse al monte. En los bordes de la historiografía que se acerca al tema puede intuirse que esto se revestía de una significación ritual (Archila, 2008), pero en la tipificación de las novelas además de confirmarse se sugiere el impacto que tenía esta acción sobre el resto del grupo que permanecía en la organización estudiantil. Ciertamente, un maoísta que decidía partir hacia el monte lo hacía como un acto de desprendimiento y entereza, pero esto no quita que también tuviera intereses secundarios. Quienes lo hacían se convertían en un mito viviente y ejemplarizante, y es indiscutible que se llevaba a cabo con una profunda convicción política, pero también con el propósito de obtener un reconocimiento social, aunque fuera para su memoria, al interior del grupo estudiantil. Irse al monte significaba, entonces, la inmortalidad, la trascendencia dentro de la organización estudiantil maoísta, lo que es comprensible además por el momento romántico e idealizado al que asistieron los estudiantes. Decimos que la cotidianidad colectiva estuvo signada por esta acción debido a que impregnaba de manera permanente el escenario estudiantil, pues constantemente se sabía de algún compañero que había partido y este era un motivo recurrente en las conversaciones, del mismo modo que cada tanto se tenían noticias de su paradero que, aunque pudieran ser falsas, alimentaban la continuidad de la participación estudiantil. Por otro lado, la cotidianidad estudiantil de 1970 estuvo también alimentada por la confluencia múltiple de grupos estudiantiles, de la misma manera que sucedió para mediados de 1960, y en cada momento los estudiantes 
desarrollaron significaciones diferentes del mundo que habitaban, y mediante ellas se relacionaban con el entorno social. Pero son las representaciones las que amplían este tema.

En los dos momentos estudiados, hubo gran diversidad de grupos estudiantiles en el escenario universitario cuya atmosfera estuvo signada por la ideología de izquierda y por las reivindicaciones políticas, pero en cuyo interior este elemento se combinaba con los anteriormente expuestos. En proporción directa a la confluencia de grupos que existieron, el escenario albergó distintas representaciones colectivas por las cuales los estudiantes significaban el mundo que vivían y orientaban sus experiencias. Nos referimos a los estudiantes que a mediados de 1960 estaban incursionando con gran decisión en las ideas de izquierda, dejando en un segundo plano los intereses gremiales para poner sus vocaciones en el país político y en la situación internacional en el preciso momento en que el padre Camilo Torres ambientaba la cotidianidad de la UN. De igual modo, nos referimos a los estudiantes que a principios de 1970 encontraron un camino en el que la izquierda se había afianzado aún más en relación con el pasado, y quienes al calor de las ideas y de la vida social universitaria estuvieron dispuestos tanto a permanecer en la clandestinidad y enjuiciar al hermano político de antaño como a entregar la vida a la causa de la revolución, es decir los estudiantes maoístas de la UdeA de 1970-1972.

En el primer caso, el trabajo de clasificación y desglose social no estuvo dado nunca por la solidaridad estudiantil entre los diferentes grupos, y por el contrario, el sentido de competencia ambientó las configuraciones de la realidad universitaria. Así, antes que de otra manera, los grupos aparecían unos a otros como competidores, por lo cual no se acudía a una valorización positiva de las cualidades de las diferentes facciones, sino que sin importar sus logros el competidor político, que siempre fue el otro, era alguien que producía cierto pesar por encontrarse en las ideas equivocadas. No obstante, tampoco merecían ayuda, y pese a que en cierta medida se esperaba que alguna vez cobraran conciencia del 
CATEDRAL Tomada: Revista de crítica literaria latinoamericana / Journal of Latin American Literary Criticism Los estudiantes tras las cámaras: el recurso de la novela para la historia.

error, tampoco se desarrollaron estrategias, por ejemplo, de extracción de militantes.

De otra parte, en las prácticas, que más bien poca referencia tienen en la novela de Fayad, se sugiere parcialmente que tanto por lograr efectos de cambio social como por hacer visible la superioridad del grupo, se desarrollaron acciones que no estuvieron propiamente direccionadas a explicitar las identidades en términos de las especificidades ideológicas, sino que se orientaron a demostrar las capacidades de despliegue de instrumentos que mostraran una mayor aptitud para afrontar las diferentes situaciones.

Un riesgo que esta investigación no soportaría sería la de ampliar la interpretación de las prácticas y sugerir apreciaciones que, en este caso tendrían más de especulación. Sin embargo, no ocurre lo mismo en relación a las formas institucionalizadas que hacían visible y perpetuaban la existencia del grupo. En ese sentido la novela precisa algunas generalidades. La puesta en escena de las elecciones para Consejo Superior fue una de esas formas institucionalizadas y objetivadas. Allí los grupos estudiantiles se esforzaron por hacer que el cargo quedara en uno de sus miembros, comúnmente aquél de quien se reconocía una apropiada formación política y ciertamente fidelidad al grupo. Este espacio de las elecciones era la instancia propicia para que los estudiantes objetivaran de forma visible la existencia del grupo, y consolidaran una posición desde la cual pudieran contribuir con sus propósitos de cambio social, pero donde también se observaban los propósitos de demostrar la superioridad del grupo. Otras instancias que permitían algo similar fueron las asambleas y los mítines, donde independientemente del asunto, se perseguían estos dos objetivos.

Sugerimos entonces que las representaciones colectivas de los estudiantes de mediados de 1960 en la UN de Bogotá, a partir del desglose, las prácticas y las formas institucionalizadas, expresan un mundo en que realmente lo gremial no perdía fuerza, por lo menos no en el terreno de las luchas de representación y de las estrategias simbólicas que expresaban las posiciones de los grupos al interior del medio universitario, de manera que la obtención de logros políticos tenía tanto 
significado como la consolidación del estatus del grupo. Estos factores orientaban las experiencias colectivas de los estudiantes, así como eran guía tanto para evaluar las prácticas como para proyectarlas.

En tanto grupos sociales los estudiantes maoístas de la UdeA de principios de 1970 tuvieron algunas similitudes con sus homólogos de la década anterior. Sucedía que también existió la cuestión de la competencia, pero ciertamente no de la misma manera. Allí esta situación fue incluso más aguda pues no sólo se trataba de una competencia por el estatus del grupo sino sobre todo del desprecio por el otro. Un desprecio fundado en la apropiación de la disputa chino-soviética que se objetivó en la repulsión de todo lo que significara 'revisionista', y fue frecuente, por tanto, que los maoístas los consideraran indignos de relacionarse con ellos. Ello sin duda ayuda a explicar los estrictos códigos maoístas que prohibían las relaciones afectivas con los integrantes de otro bando. Para estos estudiantes el otro era potencialmente un pequeño-burgués, y la realidad social universitaria estaba compuesta por los traidores y por ellos, los verdaderos revolucionarios. Quizá esto tenga que ver con que la narración de Mejía no se centre en las relaciones del maoísmo con las otras facciones sino con situaciones internas. De manera, pues, que fue el antagonismo la principal matriz de clasificación y desglose del mundo maoísta en ese contexto.

De otra parte, a diferencia de la narración de Fayad, El dedo índice presenta una mayor referencia a las prácticas y usos maoístas que hacían reconocer una identidad social y una manera propia de ser en el mundo. Comenzando por la oratoria, aquellos estudiantes se destacaban por su carisma y por la sólida apropiación del discurso político, además de las maneras gestuales recurrentes y hasta estereotipadas a que acudían, pues el título de la novela evoca precisamente un gesto particular del maoísmo de este período que consistía en un constante uso del dedo índice para señalar lo enfático de sus palabras. Asimismo, la indumentaria también expresaba una identidad colectiva y una manera propia de ser en el mundo. La ruana fue un motivo frecuente en la vestimenta maoísta y representaba el protagonismo que tenía el campesino como sujeto de revolución 
para esta ideología, además de significar, por tanto, el compromiso del maoísta con el campo, en donde según creían, debía empezar la revolución para luego expandirse a las ciudades. De igual manera, si bien no en relación directa con los demás grupos estudiantiles pero sí con los mismos maoístas en su interior, la práctica de la despedida de quien se iba para el monte también representaba una manera de hacer reconocer su identidad. La novela refiere que antes de partir el estudiante debía embriagarse. Esto cobra valor toda vez que significa la materialización de un espacio en donde se realiza el sacrificio de la vida familiar y la despedida de la vida universitaria, donde se acudía al licor con el propósito de evadir la tensión que provocaba una decisión de tales proporciones. Así pues, las prácticas y usos maoístas representaban una identidad que se caracterizaba por el buen uso del discurso, la teatralización corporal de la ideología, y una marcada tendencia al sacrificio en pro de la causa política, aunque sabemos también que implicaba una relación de reconocimiento personal al interior del maoísmo. Sin embargo, para otros grupos estudiantiles e incluso para los no comprometidos, los maoístas representaban el extremismo de la izquierda y sufrían un delirio de héroe que los hacia actuar de esa manera.

De otra parte, este asunto del sacrificio y el marcharse al campo, así como el recurso de la indumentaria, conformaban también algunas de las formas institucionalizadas y objetivadas que expresaban y perpetuaban la existencia del maoísmo. Con sólo observar cómo vestía un estudiante podía sugerirse si este era maoísta o no, y al interior del grupo la índole de la renuncia con que se vivía la incursión a la vida armada, marcaba una seña identitaria.

Sugerimos entonces que las representaciones colectivas de los estudiantes de principios de 1970 en la UdeA en Medellín, a partir del desglose, las prácticas y las formas institucionalizadas, expresan, dentro del escenario de un radicalismo izquierdista, un mundo que era vivido de manera adversa, no sólo en relación a la burguesía sino también al 'traidor interno' el cual era indigno de portar las banderas de la revolución, por lo cual las prácticas maoístas cobraban un significado redentor en tanto creían ser los llamados a la revolución ya que el 
sector tradicional del comunismo había renunciado, lo que a su vez orientaba la experiencia de los maoístas en el mundo, experiencia que, sugerimos, se vivió bajo el signo de la desconfianza debido a la incredulidad en las intenciones políticas del otro, y bajo el signo de la desolación por cuanto no sólo azotaba al mundo el yugo de la burguesía sino el declive 'revisionista' del comunismo soviético, que también podía presentar obstáculos a las tareas maoístas de la revolución.

\section{The end?}

Considerémoslo nuevamente: esta exposición ha sido un esfuerzo de desocultamiento interpretativo de algunas zonas de la inteligibilidad del sujeto en cuestión, las cuales consideramos que han permanecido como pintura sin utilizar en la paleta de colores con la cual creamos al objeto de estudio. Tampoco sobra recordar que esta manera de dar sentido a la evidencia hallada en las novelas, no pretende ninguna ruptura altanera dentro de la tradición de estudios que se han dedicado al tema, sino que su propósito ha sido el dar una vuelta más a la tuerca de la comprensión.

Este ejercicio permitió observar que la vida de los estudiantes, como era de esperar, se movía también en un registro diferente del que se ha acostumbrado a ver; en todo caso, permite recordar la historia de los estudiantes de un modo talvez un poco más confidencial, tan preocupados por el reconocimiento social interno como por generar cambios sociales definitivos. Se puede destacar lo siguiente: la lucha y el agite del momento histórico se vivió tanto en el plano convulso de lo político, como en el plano privado de los afectos, el comedor y el más sencillo y terrenal diario a diario. ${ }^{19}$

\footnotetext{
${ }^{19}$ Este ejercicio también, a título personal, le permitió al autor gozar la lectura de novelas de una manera muy especial; una manera que no separa tajantemente la literatura de la bibliografía, sino que sospecha, con esa curiosidad con la que un niño escarba una bolsa de juguetes nuevos, o con esa avidez con que encuentra otros usos a sus juguetes preferidos y convierte, pongamos por caso, un patín en un automóvil de carreras, y logra hacerle pensar sonriente en un tejido en el que las narraciones noveladas y la bibliografía académica puedan hacer parte de la misma trama. Aquí,
} 


\section{Bibliografía}

Acevedo, Álvaro. "Representaciones discursivas y memoria en la cultura intelectual universitaria”. Revista de ciencias humanas 36 (2007): 97-112.

------. “Juventud y protesta global hoy: por un análisis retrospectivo". Revista Científica Guillermo de Ockham, 10/1(2012): 15-25.

Acevedo, Álvaro, \& Samacá, Gabriel. "Revolución cultural en América Latina: el movimiento estudiantil como objeto de estudio en la historiografía colombiana y continental". Memoria y sociedad 31 (2011): 104-119.

-------. "Juventudes universitarias de izquierda en Colombia en 1971: un acercamiento a sus discursos ideológicos". Historia Caribe, VIII/22 (2013):195-229.

Álvarez, Gustavo. El titiritero. Bogotá: Plaza y Janes. (1979).

Achila, Mauricio. El maoísmo en Colombia: la enfermedad juvenil del marxismoleninismo". Controversia 190 (2008): 146-195.

-------. "El movimiento estudiantil en Colombia, una mirada histórica”. Revista del observatorio social de América Latina 31 (2012): 71-103.

extendemos un agradecimiento al profesor José Abelardo Díaz Jaramillo, quien con una frase interrogaba nuestras ideas y ponía en marcha nuestras propias propuestas por más que nosotros mismos las desconociéramos: “¿Cómo sería eso?”, suele decir con un tierno e inquietante modo socrático. Con seguridad esa frase nos hará seguir teniendo curiosidad, capacidad de asombro y de imaginación histórica.

Por último, el apartado final es en sí mismo una propuesta que resulta de considerar positivamente la implementación de la novela como fuente para la historia, a partir del caso práctico de esta aproximación a la vida de los estudiantes, y que se propone alentar el uso de la novela en esta perspectiva. La novela como fuente -hay que precisarlo- especialmente para la historia cultural, rama de la disciplina preocupada por los procesos de construcción del significado, que quizá como ninguna otra encuentra en la novela una fuente hecha a la medida de sus preocupaciones. De manera que invitamos a seguir leyendo novelas, agregando un sentido y curiosidad histórica en nuestras lecturas, que pueda hacer posible pasar de la sospecha del guiño temporal a la sistematización de las reflexiones al respecto y a la reconstrucción histórica a partir de la literatura. 
Bourdieu, Pierre. "La construcción del objeto". El oficio del sociólogo Presupuestos epistemológicos.Pierre Bourdieu, J.-C. Chamboredon, \& J.-C. Passeron. Buenos Aires: Siglo XXI. 1975. 51-81.

Caballero, Antonio. Sin remedio. Bogotá: Oveja Negra. (1984).

Capote, Virginia. "Compañeros de viaje de Luis Fayad, un retrato sociocultural de la Bogotá de los sesenta". Tonos digilta: Revista electrónica de estudios filológicos 25 (2013).

Caycedo, Jaime. "Conceptos metodológicos para la historia del movimiento estudiantil colombiano". Revista Estudios Marxistas 27 (1984): 48-60.

Celis, Juan. "Los orígenes de la contestación universitaria en Medellín entre 1957 y 1968". Revista electrónica Diálogos de derecho y política 1. (2009) Recuperado el 10 de agosto de 2013, de http://www.slideshare.net/Dialogosudea/revistaelectrnica-dilogos-de-derecho-y-polticanmero-1

Chartier, Roger. El mundo como representación. Estudios sobre historia cultural. Barcelona: Gedisa, 2005.

Corsi, Luis. Los estandartes rotos un episodio obrero-estudiantil. Bogotá: Tercer Mundo. (1973).

Cote, Jorge. "El movimiento estudiantil de 1971: entre la homogeneidad y la heterogeneidad". Una historia inconclusa: izquierdas políticas y sociales en Colombia. Mauricio Archila, Editor.Bogotá: Cinep-Colciencias-Programa por la Paz, 2009. 413-462.

Díaz, José. El Movimiento Obrero Estudiantil Campesino 7 de Enero y los orígenes de la nueva izquierda en Colombia 1959-1969 (Tesis de maestría). Universidad Nacional de Colombia, Bogotá. 2010.

-------. “Juventud, nueva izquierda y revolución en Colombia: los avatares políticos de Antonio Larrota González”. Controversia 194 (2010): 265-291.

-------. "Del liberalismo al maoísmo: encuentros y desencuentros políticos en Francisco Mosqueda Sánchez, 1958-1969”. Anuario Colombiano de Historia Social y de la Cultura, 38/1 (2011): 141-176. 
CATEDRAL Tomada: Revista de crítica literaria latinoamericana / Journal of Latin American Literary Criticism Los estudiantes tras las cámaras: el recurso de la novela para la historia.

------. "El 8 de junio y las disputas por la memoria, 1929-1954". Historia y sociedad 22 (2012):, 157-189.

Elias, Norbert. "Ensayo teórico sobre las relaciones entre establecidos y marginados". $\mathrm{La}$ civilización de los padres y otros ensayos. Norbert Elias Santa fe de Bogotá: Norma. 1998.

Entrevista a Mejía, Juan Diego, realizada por León. I.R, [Geniusapiens], Bogotá, abril 4 de 2010. https://www.youtube.com/watch?v=wL4GkTI5Un0 (mayo 10 de 2012).

Fayad, Luis. Compañeros de viaje. Bogotá: Tercer Mundo, (1991).

Gilman, Claudia. Entre la pluma y el fusil. Debates y dilemas del escritor revolucionario en América Latina. Buenos Aires: Siglo XXI. (2003).

Hernández, Rodolfo."El Davis, génesis del maoísmo en Colombia: incidencia del pensamiento Mao Tsé-Tung en el sur del Tolima”. Revista Goliardos 16 (2012): 77-87. Recuperado dehttp://revistas.unal.edu.co/index.php/gol/article/viewFile/44884/46290

Jaramillo, Darío. Cartas cruzadas. Bogotá: 1993. (1993).

Le Bot, Yvon. "El movimiento estudiantil durante el Frente Nacional (1958-1974)". Ideología y sociedad 19 (1976): 49-70.

Leal, F. (1984). "La participación política de la juventud universitaria como expresión de clase". Juventud y Política en Colombia. M. Cárdenas, y A. Díaz, Editores Bogotá: FESCOL-Instituto SER, 1984. 155-203.

López, Rodrigo. "La novela como fuente histórica de la cultura: ideas para un consenso". En proceso de edición por Revista Historia Caribe 28 (2015)

Manrique, Miguel. Disturbio. Bogotá: Seix Barral. (2009).

Marín, Paula. "Perozzo y Fayad: dos tomas de posición antagónicas en el campo de la novela colombiana de los setenta". Estudios de Literatura Colombiana 24 (2009): 47-64.

Melo, Jorge. Algunas consideraciones globales sobre "modernidad" y "modernización" en el caso colombiano. http://www.jorgeorlandomelo.com. (febrero 2 de 2014).

Mejía, Juan. El dedo índice de Mao. Bogotá: Norma. (1993). 
Mejía, Orlando. La generación mutante: nuevos narradores colombianos. Manizales: Universidad de Caldas, 2010.

Molano, Frank. El imaginario maoista 1965-1982 como mentalidad revolucionaria en la izquierda colombiana (Tesis de maestría). Universidad Nacional de Colombia, Bogotá. 2004.

------. "La izquierda maoísta colombiana: organizaciones y mentalidades en la década de 1970”. Para rescribir el siglo XX. J. Guerrero, O Acuña, Editores.Medellín: La carreta editores y Universidad Pedagógica y Tecnológica de Colombia, 2011. 351-375

Peña, Isaías. La generación del bloqueo y del estado de sitio. Bogotá: Punto Rojo. 1973.

Ruiz, Manuel. Sueños y realidades. Procesos de organización estudiantil 1954-1966. Bogotá: UNIBIBLOS. (2002).

Soto, Fernando. Los funerales de América. Bogotá: Plaza y Janes. 1980.

------. La siembra de Camilo. Bogotá: Plaza y Janes. 1971.Villamil, Eduardo. "Rompiendo esquemas: discusiones, consignas y tropeles del estudiantado universitario en Colombia en 1971". Controversia 194 (2010): 233-263. 